\title{
A neglected family resource for saving newborn lives - the grandmothers
}

Judi Aubel, PhD, MPH

https://doi.org/10.31219/osf.io/pyc63

\section{INTRODUCTION}

The first days and weeks of life are critical for all newborns, especially in low resource contexts in the Global South. Approximately $75 \%$ of newborn deaths occur in the first week after birth, $40 \%$ on the first day after birth and the majority occurring at home.[1] The family environment in which newborns begin life is critical to their health and survival and newborn policies and programs should be based on an in-depth understanding of family contexts and dynamics. Current global efforts to promote newborn survival give limited consideration to intra-household roles and influences related to newborn care.

Despite increased global commitment to reducing newborn deaths, the reduction of neonatal mortality (NMR) has been slow.[2] Essential family-level practices that contribute to newborn survival have been identified related to early and exclusive breastfeeding, thermal care, hygiene and prompt care-seeking when danger signs are observed.[3] However, efforts to improve newborn care and reduce NMR have mainly focused on strengthening health services with effective technologies and practices.

While investments in newborn care have increased, several critical contextual factors have received limited attention. First, across the Global South, newborns spend most of their first 28 days in families, whether they were born in a facility or at home. Consequently, newborn care and survival depends largely on family caregivers' practices. Second, all non-western cultures recognize the precarity of the newborn period and have endogenous strategies to promote newborn survival, including culturally-designated roles conferred on different family members. [4] Last, in these collectivist socio-cultural contexts, along with young mothers, various extended family members are involved in newborn care and in advising young mothers on newborn practices.

The purpose of this article is first, to present the rationale for conceptualizing newborn care within culturally-constructed family systems and second, to provide examples of research from cultures 
across Africa, Asia and Latin America that document the role and influence of senior women, or grandmothers, on newborn care.

\section{Conceptual framework for this discussion}

My discussion of newborn care within family systems is framed by several concepts related to the structure and dynamics of non-western collectivist cultures that have received limited attention in global efforts to promote newborn survival.

\section{Culture: a neglected parameter in global health}

For many years, anthropologists have lamented the limited attention given to cultural parameters in public health programs.[5] Present-day anthropologists decry the continued disregard for culture in health research and interventions.[6] They assert that culture is a fundamental determinant of health, yet it is given limited attention in health-related research often leading to culturally-blind interventions. They also argue that health research and intervention frameworks consistently reflect individualist values and a Eurocentric view of nuclearized families, both incompatible with non-western, collectivist societies.

Few researchers from the Global South have clearly addressed the ubiquitous disconnect between health services and cultural context. Airhihenbuwa (1995) articulates these concerns in his seminal book, Health and Culture: Beyond the Western Paradigm. He argues that public health programs in Africa have "consistently undermined, and in most cases ignored the centrality of culture" often resulting in culturally inappropriate interventions. He argues that programs should reflect African cultural codes and meaning rather than those of the Western paradigm.[7] Similarly, from an Asian perspective, Kumar and colleagues (2010) discuss the primacy of the sociocultural context in community health and assert that many newborn interventions are culturally blind.[4]

Many international health organizations claim that their programs build on cultural realities but often this discourse is not operationalized. This gap between rhetoric and practice appears to be due in part to inadequate clarity on the parameters of culture. Weidman (1988) delineated two key dimensions of health culture: first, the cognitive and normative health-related values and beliefs; and second, the social system including roles, relationships and health-seeking strategies.[8] Public 
health research and interventions have primarily focused on the first dimension, dealing with individual psychological factors while giving limited attention to the second dimension of health culture regarding family and community contexts.[9]

\section{Characteristics of collectivist cultures}

Cultural values and structures have a decisive influence on family strategies concerning both household newborn care and use of newborn health services. Anthropologists categorize cultures globally on a continuum from individualist to collectivist with more than $70 \%$ being fundamentally collectivist.[10] In collectivist cultures "from birth onwards people are integrated into strong, cohesive groups, often the extended family, which continue protecting them in exchange for unquestioning loyalty".[11]

Salient characteristics of collectivist cultures that influence $\mathrm{MCH}$ and that should orient policies and programs include: social hierarchy based on age and experience, elders teach and younger people learn from them; gender-specific roles; multi-generational families and collective childrearing; collective decision-making; and the expectation that individuals will conform to group norms.[12] Another fundamental feature of collectivist cultures are strong relationships between individuals, with interdependency valued, with individual autonomy discouraged and collectivist decisionmaking being normative.

The onion model [Figure 1] visualizes the position of individuals nested in family, community and cultural systems [12]. In Asian communal, or collectivist, cultures, Kim and colleagues (2008) explain that individuals view group goals as primary, while personal beliefs and goals are

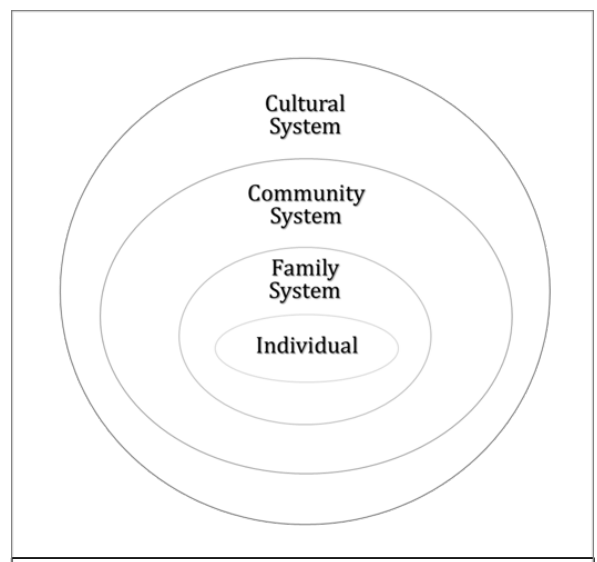

Figure 1: Onion Model. (Aubel \& Rychtarik, 2015) secondary.[13] Kumar and colleagues echo this idea in their discussion of the contrast between the western value of individual agency and the non-western value of collective agency in the Indian context [14]. Similarly, based on the African concept of Ubuntu, individuals value interdependency over autonomy [15]. In similar terms, Turkish psychologist, Kagitcibasi, contrasts western cultures of separateness with eastern cultures of relatedness and interconnectedness [16]. For a young pregnant or lactating woman in Mali, Bangladesh 
or Bolivia, embedded in the onion, it is extremely difficult for her to reject the expectations of family, community and culture. Rather, she is expected to conform to those expectations, while at the same time she benefits for support from those around her.

Another related point regarding collectivist family values is raised by anthropologist Imorou and colleagues [17]. They explain that in African cultures, a child belongs to, and is the responsibility not only of his/her biological parents, but also of the wider, extended family. From research in 5 West African countries, Kane drew the same conclusion regarding the extended family's collective responsibility for raising a child [18]. This characteristic of collectivist cultures, with clear implications for newborn research and interventions, is largely overlooked in global health frameworks and interventions. This oversight contributes to the narrow focus on biological parents and their offspring.

\section{Household Production of Health}

Historically, community health interventions have primarily focused on formal health systems while neglecting family health systems. Recognizing that the health of children is primarily a product of family caring practices, in the early 1990's, several social scientists argued that the child survival revolution was excessively focused on technologies and health services, and that it gave inadequate attention to the multi-faceted intra-household context.[19] They proposed the Household Production of Health (HPH) framework contending that the major determinants of child health emanate from within households and, therefore, community health interventions should be grounded in a comprehensive understanding of intra-household roles, dynamics and decisionmaking.

The HPH initiative emphasized the influence of cultural factors on child health-related norms and behavior and identified three culturally-determined aspects of non-western households which should inform development of interventions: 1) various categories of household actors care for children; 2 ) routines of men and women are gender-specific and 3) child health practices are culturally prescribed, e.g. how infants should be carried or breastfed.[20]

The HPH platform proposed a profound conceptual shift in $\mathrm{MCH}$, from a narrow focus on women and children to an inclusive family systems approach [19-20]. While the unconventional HPH work has been largely forgotten, current interest in socio-ecological, or systems, approaches to addressing health issues echoes the perspective of the HPH pioneers. 


\section{Reconsidering the mother-child dyad}

A key concept in $\mathrm{MCH}$ in western public health policies, research and programs is the mother-child dyad, rooted in the risk group orientation and in the nuclear family model. In the Global South, this concept has been widely adopted by public health researchers even though it is incompatible with the structure of non-western collectivist cultures wherein mothers and children are embedded in extended, family systems.

The fields of nursing and social work embody a family systems perspective on issues related to women's and children's health [21-22], however, public health's adoption of a systems, or socioecological, frame is relatively recent and not yet widely embraced by programs in the non-western world [23]. The misfit between the reductionist mother-child dyad frame and the influence of extended families in collectivist cultures is reported by Schrijner and Smits [24] who analyzed household structure in 31 Sub-Saharan African countries. "Most mother-child dyads are not selfcontained units but are part of a larger family system in which mothers are supported by other family members and in particular by grandmothers".[24]

A small, but growing, body of research on collectivist cultures in the Global South looks beyond the mother-child dyad and biological parents, elucidating the roles and influence of both kin and nonkin advisors and caregivers in $\mathrm{MCH}$ [25]. In many cases, this work is led by researchers from the Global South, who are perhaps more experientially attuned to the collectivist and multigenerational family contexts in which mother-child dyads are embedded. This expanding corpus of research on $\mathrm{MCH}$ topics offers increased insight into the structure and dynamics of family systems and consistently reveals the central role of senior women, or grandmothers, not only in rural contexts, for example, in India [26], Ethiopia [27] and Brazil [28] but also in urban settings, in Nairobi [29], Accra [30] and Quito [31]. Reflecting a systemic view of families in collectivist Brazil, researchers discuss the child-mother-grandmother triad at the center of all $\mathrm{MCH}$ issues [32].

\section{Social hierarchy based on gender, age and experience}

Collectivist cultures are hierarchically structured, and authority is associated with age and experience. "Behaviors are passed on from older, more experienced actors to younger, lesser experienced actors" [4]. In collectivist cultures, the roles of men and women are gender specific and as both advance in age and experience, their authority in their respective domains of expertise 
increases. For all matters related to women's and children's health, major responsibility lies with female family members whose knowledge and experience increase with age [25]. Consequently, across non-western cultures, families recognize senior women as authorities on all aspects of child development, often advising men on the support they should provide. Karmacharya and colleagues conclude that "In Southeast Asia, grandmothers are considered storehouses of knowledge and wisdom on a wide array of household topics" regarding child health [33]. Altaye and colleagues in Ethiopia discuss the family power structure wherein older women and husbands play complementary decision-making roles regarding pregnancy and newborns [27].

In Kane's research in 5 West African countries, she observed the role of influential networks of senior female kin and non-kin in newborn care [18]. She explains that the arrival of a newborn is an occasion for these older women, specifically the paternal grandmother, to affirm their authority within the family. Kane concludes that in West Africa, paternal grandmothers' powerful role coordinating newborn care is bolstered by two factors: first, recognition within the family sphere of their vast experience and as guardians of valued traditional practices; and second, they are mothers-in-law of the young mothers, thereby according them authority over daughter-in-law's children. Given this gendered power hierarchy in West African families, Kane concludes that a young mother is expected to show deference to grandmothers and aunties and that her ability to oppose their instructions is very limited.

\section{Limitations of current newborn health frameworks}

Neonates are embedded in families where they are cared for by various family members. Unfortunately, newborn policy frameworks give limited attention to the roles, knowledge and relationships between different family caregivers. For example, in the 2014 WHO/UNICEF Every Newborn Action Plan, one of the strategic objectives is to harness the power of parents, families and communities, however, it makes no reference to intra-familial roles beyond that of parents [34]. UNICEF's 2018 framework, Every Child Alive identifies priorities to improve health facility newborn care but makes no mention of the need to strengthen family-level newborn caregiving [2]. Several factors appear to contribute to the limited attention given to the roles and influence of wider family members on newborn care: the medicalized focus on formal newborn health services; the Euro-centric assumption that mothers are primary and autonomous newborn care-givers [7]; inadequate understanding of multi-generational caregiving in collectivist societies; the 
predominant deficit model in public health which ignores community assets [35]; and ageist biases, particularly against older women.

\section{EVIDENCE OF GRANDMOTHERS' ROLE IN NEWBORN CARE}

In this second part of the paper, I present examples of the role and influence of grandmothers related to various facets of newborn care, drawn from qualitative research conducted in more than 80 cultural contexts in 29 countries in Africa, Asia and Latin America. The studies cited represent an eclectic body of qualitative research which I compiled over the past 10 years, from the fields of public health, nursing, anthropology and social work, produced since 2000 in English, French and Spanish. Studies referred to are primarily from published sources, but also from grey literature collected mainly through personal contacts with international development organizations. Many published studies were identified using these key words: newborns, neonatal and grandmother. However, a major constraint using an approach based on key words is that grandmother rarely appears as a key word even though in the body of many articles their role is discussed. Many studies were identified by manually scanning journals in the above-mentioned fields.

\section{Grandmothers' role as authoritative advisors and caregivers}

An earlier review presented extensive evidence of the role of senior women, collectively referred to here as grandmothers, as advisors and caregivers on child nutrition in the non-western world [25]. Here, research findings from Africa, Asia and Latin America provide evidence of the dual-faceted role of grandmothers coordinating and providing newborn care and coaching young mothers on culturally-prescribed practices. From Africa: Ethiopia [36]; Ghana[37,38]; Kenya[29]; Benin[17]; Mauritania[18,39]; Malawi[40-41]; Niger[42]; Nigeria[43]; Egypt[44-45]; Burkina Faso[46-47]; Somalia[48]; Senegal[49-50]; Zambia[51]; Nigeria, Tanzania, and Ethiopia[52]; Mali[53-55]; and Uganda[56]. From Asia: India[26,57-60]; Pakistan[61]; Nepal[33]; Bangladesh [62]; Indonesia [63]; and Uzbekistan. (Barrett, 2008) And from Latin America \& the Caribbean: Brazil[28, 32, 64]; Mexico[65]( Ramos, 2014); Costa Rica[66]; Guatemala (Bixiones, 2007); Colombia[67]; and Haiti (Kadima, 2018).

Research conducted in a wide variety of socio-cultural contexts across the Global South (listed above) reveals similar gender-specific and age-specific roles of family members in newborn care and consistent recognition of grandmothers' expertise and authority. For example, two studies in 
Ghana conclude, "parents consider grandmothers as the epitome of wisdom and knowledge regarding newborn care"[30 p.5] and it is the husband's mother who calls the shots on newborn care[37]. Research in Nepal concludes that advice of revered and authoritative grandmothers cannot be refused [33]. In India, Prusty and Unisa report on the influence of grandmothers within the web of social relationships surrounding and influencing younger mothers [26]. In Brazil, Gross and colleagues report that young urban mothers referred to grandmothers as their eternal guides and expressed appreciation for grandmothers' guidance, "They brought security and comfort justified by the experience accumulated by these women"[32,p.537]. And research on breastfeeding in urban Mexico concludes that "grandmothers continue to play a leadership role in families as primary advisors and health promoters" [Ramos thesis, 2014,p.40\}.

\section{Inculcating cultural norms and practices}

In studies reviewed from numerous cultural contexts, a similar pattern emerges: newborn care is a culturally-designated and gendered role coordinated by older women; younger women are learners; and men are rarely directly involved, while providing logistical and financial support when needed. This pattern is reported across the Global South, for example, in Niger,[42] Benin,[17] Uganda,[56] Burkina Faso,[46] Indonesia,[63] Mexico, (Ramos, 2014) Brazil,[32] and India[58]. In collectivist cultures in all three continents, mothers are embedded in family systems organized hierarchically by age and experience and they are expected to defer to the advice of senior women. Iganus and colleagues' research in 4 African sites reveals both young mothers' dependency on experienced grandmothers and inability to refuse their advice, where often "mothers themselves only took full responsibility of newborn care after a few days or weeks".[52,p.1262] Similarly, researchers in Nepal describe the transmission of traditional newborn practices from revered grandmothers to young mothers who cannot refuse their directives. [33]

Many studies document younger women's adherence to grandmothers' traditional advice on infant care, given their trust and respect for them, even when it conflicts with health workers' advice in Malawi,[41] Mauritania,[18] and India.[26]

Research in numerous non-western contexts reveals that older women inculcate in younger mothers an array of culturally-prescribed practices pertaining to: massage; cord care; colostrum; prelacteals; thermal care; breastfeeding; newborn illness; and spiritual protection, and that 
grandmothers' efforts are intensified with primiparas, anticipating that with subsequent births those practices will be replicated, for example, in Uganda.[56] While certain traditional newborn practices perpetuated by grandmothers are beneficial, others are not, such as giving prelacteals and withholding colostrum. In Northern Ghana, Gupta and colleagues documented grandmothers' role preserving ancestral traditions regarding placenta burial, breastmilk stimulation and newborn home remedies.[37] In Karnataka, Kesterton and Cleland documented grandmothers' role initiating young mothers to the use of prelacteals, cord and thermal care.[68] In Egypt, from the first days of life grandmothers give herbal drinks to newborns to stop babies from crying and help them sleep at night. [44] In Nigeria [43]and Ghana [69] researchers documented grandmothers' harmful practices giving water, prelacteals and traditional medicines. In urban Brazil, Susin and colleagues documented grandmothers' administration of traditional teas and water to newborns,[64] while in Nicaragua grandmothers give newborn oil and honey to clean their stomach.[70]

\section{Seclusion of mothers and newborns: protecting and teaching}

In many cultural settings, initial newborn care, protection and feeding involve seclusion of infants and mothers, for varying lengths of time, usually under the supervision of an experienced grandmother or other senior female family members. In Uzbekistan, the chilla period lasts 40 days where newborns and mothers are isolated with the paternal grandmother who provides culturallyappropriate care and coaching (Barrett, dissertation, 2008). In Karnataka, during 40 days of confinement[62] and during 6 days of chhatiyar in Nepal, grandmothers transmit their experience related to all aspects of newborn care and feeding, to daughters-in-law.[71] In Senegal, 7 days of seclusion protects newborns from the mystical we illness.[49] Studies in numerous other cultural contexts describe this protective and educational period of isolation for babies and mothers, including in: Indonesia,[63] Niger,[42] Burkina Faso,[46] India;[4,72] Bangladesh [62] and Amazonia.[24]

\section{Grandmothers' role in breastfeeding}

There is extensive evidence of the influence of grandmothers on young women's decision whether to breastfeed and for how long. Health workers are expected to advise young mothers on optimal breastfeeding practices. While such advice may be provided during health facility deliveries, with home deliveries and in the post-natal period across all three continents, most women benefit from in-house breastfeeding coaches, namely grandmothers and other experienced female family 
members. There is evidence of the role of these experienced advisors, especially with primiparas, from Ghana,[73] Benin [17] and Brazil.[64] Diagana and Kane (2016) conclude that "In Mauritania, as in other West African societies, grandmothers are on the frontline of infant feeding".[74,p.242] In Bihar, mothers-in-law are primary decision-makers on breastfeeding initiation, practices and problems.[58]

In urban Ecuador, most new mothers (84\%) identified grandmothers as their primary advisors on breastfeeding, while the others (16\%) cited other older female kin and non-kin. [31] In urban Mexico, Ramos (Thesis, 2014) found that grandmothers' advice was the main factor that either encouraged or discouraged young mothers from breastfeeding. Results of social network analysis by other Mexican researchers showed that most women (94.7\%) were primarily encouraged to breastfeed by maternal grandmothers, while less encouragement came from doctors (57.9\%) and from paternal grandmothers (42.1\%).[75]

Some studies report on grandmothers' advice to increase breastmilk production. In Nicaragua, [70] grandmothers advise various foods and liquid drinks and in urban Bangladesh, [76] both kin and non-kin grandmothers advise lactating women to eat certain foods.

Researchers report that grandmothers, and other senior female family coaches, who are not supportive of science-based exclusive breastfeeding, typically advise based on their empirical experience and cultural norms in Nepal[77], Malawi, [41], Brazil [64] and India, 4,68] Consequently, new mothers are often confronted with contradictory advice received during infrequent contact with health workers and from omnipresent senior family advisors. In Ghana, researchers found that when grandmothers' and health workers' advice differs, mothers often view grandmothers as the authorities and defer to them.[30]

In many cultures, grandmothers convey traditional ideas that some breastmilk is of poor quality and/or insufficient quantity, both ideas refuted by nutritionists. In Zambia, a major concern of grandmothers is insufficient milk.[51] In Egypt, researchers found that grandmothers often conclude that breastmilk is of poor quality when a baby cries after breastfeeding, justification for giving herbal drinks to supplement breastmilk.[44] Curiously, in both Ghana [69] and in Senegal 
[50] grandmothers conduct the same test, involving putting an ant into a spoonful of breastmilk to determine its quality. If the ant dies, this confirms the breastmilk's poor quality.

\section{Care of sick newborns}

Most research on newborn illness focuses on formal health services and technologies. Few studies have systematically investigated household-level strategies to care for sick newborns and even fewer have examined family care for premature infants. Evidence from various non-western contexts reveals that during neonatal illnesses, families recognize grandmothers' expertise to diagnose problems, to propose home treatment and to recommend referral to extra-familial resources when necessary. In Ghana, Bazzano and colleagues concluded that "Older women and grandmothers are often the ones who decide that a child is in need of treatment and often also determine the type of treatment due to their authority within the household and the community". [38,p.125] Similar findings on grandmothers' central role in caring for sick newborns are from Mali,[53] Indonesia,[63] Malawi,[78] India.[57,59,79] From Nepal, Lama and colleagues found that decision-making around newborn illness is a collective process mainly involving female family members, with husbands playing a limited role.[71]

In many societies there are mystical newborn illnesses that medical doctors do not understand. Studies in Malawi,[78] India[79] and Senegal[49] report that communities recognize grandmothers' expertise regarding these illnesses. In Nicaragua grandmothers describe newborn illnesses due to the evil eye ( $m a l$ de ojo) that doctors cannot treat but that they treat at home.[70] Another folk illness, empacho, which exists all over Latin America, is treated outside the formal health system by grandmothers, aunts and female neighbors.[80]

With pre-term and low birth weight (LBW) babies, families recognize that special expertise is required. Research in several contexts documents the intensified role of grandmothers in these situations. In two different areas in Ghana, Schuler and colleagues conclude that "the care of LBW babies is the core responsibility of grandmothers" [81,p.44] and Adama and collaborators report that families recognize that care of premature infants is within the cultural domain of grandmothers and they rely on grandmothers' experience in these challenging situations.[30]

\section{Indigenous newborn support systems}


In collectivist non-western cultures, solidarity and reciprocity are primordial values reflected in the spirit of cooperative breeding [82] and embodied in ubiquitous women-centered, multigenerational indigenous support systems for women and children.[25] Surprisingly, the significance of these social support networks to pregnancy, newborn and child health has been largely unexplored by researchers in the Global South. An early observer of these naturally-occurring networks was South African, Steuart, who referred to them as primary friendship groups.[83] In Mali, Adams and colleagues identified four types of support provided by these social networks related to child health: practical, informational, emotional, and material or tangible assistance.[84] The importance of these social networks on newborn care has been neglected in most newborn research, reflecting a Eurocentric and reductionist focus on nuclear families and mother-child dyads.

A few studies have investigated the influence of these gendered and intergenerational networks, composed primarily of women, both kin and non-kin, and wherein experienced older women play a leading role in Nepal;[82,85] Benin,[17] Malawi.[78] In recent research in Odisha, Prusty and Unisa describe the reach of these indigenous social support networks, or webs of social influence, that support newborn care as "powerful disseminators of knowledge" for young mothers.[26] A significant finding from their research in India is that the health-related knowledge of less-educated women is more influenced by their social networks, composed primarily of older women, than by formal health workers.

In all contexts, these social network members convey certain expectations to younger women regarding the do's and don'ts of newborn care, while providing younger women with emotional support and advice. Most research on newborn care that discusses grandmothers' role, focuses on their knowledge and practices, while giving little attention to the significance of the emotional and social support they provide to young mothers. Costa Rican researchers, Sedo-Masis and colleagues, discuss the importance for young mothers of the red de apoyo provided by the grandmother social support networks.[66] From two different contexts in Brazil, Piperata [28] and Gross and colleagues [32] describe the invaluable contribution of these networks in creating social bonds between women around newborn care which often become ongoing bonds of reciprocity and support.

\section{Men's role in newborn care}


While many current $\mathrm{MCH}$ programs target fathers, there is limited in-depth research on men's roles in $\mathrm{MCH}$ within family systems in non-western contexts. Regarding newborn health, many studies from different socio-cultural contexts report that men do not play an active role either in direct caregiving nor in day-to-day decision-making concerning newborns. Numerous studies do conclude, however, that men play important supporting roles, primarily logistical and financial, for example, in: Benin;[17] Ghana;[37] Malawi;[78] Burkina Faso;[46] Mali;[53] Niger;[42] Somalia;[48] Senegal;[49] Sri Lanka;[86] Nepal;[71,77] Indonesia;[63] Zambia;[51] Ethiopia;[36] and Nicaragua.[71]

Similar findings regarding men's limited involvement in newborn spaces, except when serious problems arise, are reported by Iganus and colleagues from research in four African contexts. Their research found that "physical and social spaces related to newborn care were closed to men, that men were perceived to lack the ability to care for the newborn and had little physical contact with the baby, but as head of the family, they were often the symbolic decision-makers and the financial provider".[52,p.1263] In many cultural contexts, at least the first days after birth, men are excluded from gendered newborn spaces as families recognize that newborn care requires specialized expertise which men do not have. [25] It is often erroneously assumed that men, as heads of household, are primary decision-makers on all family issues. The evidence reviewed here supports the notion that regarding newborn care, men are usually not central decision-makers and more often are advisees of experienced women.[25]

When newborn illnesses occur, research across non-western cultures reveals that men typically confide in experienced women within the family, while providing logistical and financial support when needed.[ 85,86$]$ Cross-country research on family care-seeking for newborns, on data from Ethiopia [36], Nepal, [71] SriLanka, [86] India [89] and Uganda,[87] identified a common pattern that fathers do not play a key role recognizing newborn illnesses. In Nepal, Lama and colleagues found that decisions related to care-seeking were made by female family members, namely, the mother, grandmothers and aunts.[71] In Uganda, Okuga and colleagues concluded that "key decision-makers were mothers and mothers-in-law of sick newborns. They determined where the baby would be taken for care and at what point of the illness. The role of the husbands was to provide finances for care-seeking". [87,p.79] In Uttar Pradesh, Aruldas and colleagues observed 
that when there are complications it is experienced women in the family who decide what should be done at home, at the community and/or facility levels.[87]

A present trend, emanating from the Global North, is the promotion of men's involvement in all aspects of $\mathrm{MCH}$, including newborn care, based on the assumption that greater men's involvement is advantageous. Several researchers have questioned this assumption, expressing concern that increased men's involvement and authority in the newborn space can inadvertently disempower women and disrupt the women-to-women support system for mothers and neonates. In Ghana, researchers questioned women on the desirability of men's involvement in newborn care. Some interviewees stated that they did not want men to be involved in the female-managed newborn space.[90] The researchers signal the potential risk of increased men's involvement in newborn spaces, proposing that "the effect of male involvement on women's autonomy and the real impact on health outcomes should be considered in intervention design."[90,p.269] A similar concern is expressed by Iganus and colleagues based on their research in multiple African settings. They warn that "care must be taken to ensure that interventions to involve men do not result in disempowerment of female family members".[52,p.1263] These researchers question the frequent assumption regarding men's foremost authority on newborn and other MCH issues.[52,90]

\section{CONCLUSIONS}

This discussion of evidence on family level newborn care in African, Asian and Latin American contexts provides insight into an aspect of newborn health that heretofore has been given limited attention - the role and influence of grandmothers. A growing body of evidence from across nonwestern, collectivist societies reveals the culturally-designated role of these experienced, older women as newborn advisors and caregivers. Unfortunately, at the global level, newborn research, policies and interventions continue to focus primarily on medical technologies and services,[91] while giving limited attention to intra-household newborn strategies in which grandmothers are key actors and components of families' socio-cultural operating systems.[4] Research reviewed from 80 cultural contexts across Africa, Asia and Latin America reveals significant commonalities across cultures regarding the core roles played by grandmothers, while their culture-specific practices with newborns can vary greatly from one culture to another. For example, in Northern Ghana, Gupta and colleagues drew these conclusions on grandmothers' core roles [37,p.9] 
Grandmothers play an integral and multi-faceted role in maternal and infant health. Grandmothers support mothers during pregnancy, care for infants following delivery, maintain cultural traditions surrounding pregnancy and childbirth and serve as repositories of knowledge on local treatment options.

This description of Ghanaian grandmothers' roles during pregnancy and with newborns are virtually the same core roles of grandmothers identified in all studies from all three continents included in this review.

Grandmothers' central role in newborn care in non-western societies emanates from the fundamental values and structure of collectivist cultures where: reciprocity and solidarity are key values; the social hierarchy within families is based on gender and age; roles are gender-specific; social norms are transmitted from older to younger women; there is a strong sense of collective responsibility for children, especially among female caregivers; and decision-making is collective with experienced elder women having status and authority. A vital social resource in collectivist cultures to address all issues related to women and children, and that is specifically beneficial to newborns, are the indigenous social support networks of women, both kin and non-kin, who collaborate to ensure optimal newborn care at the family level [25]. These networks are a manifestation of what evolutionary anthropologists refer to as cooperative breeding whereby mothers receive support from others, mainly female kin, but also non-kin in their friendship networks in raising their offspring. [82, 91-92]

Many studies report that often grandmothers do not have up-to-date knowledge regarding, for example, exclusive breastfeeding, and that they advise traditional practices such as giving prelacteals and water to neonates, both actively discouraged by health authorities. And many studies report on the discord that this creates between powerful grandmothers and their respectful young daughters or daughters-in-law who often hesitate to contest their senior advisors' instructions even when they know that they conflict with health workers' advice.

This review provides considerable evidence of grandmothers' decisive role in newborn care in families across the Global South based on a growing, but still minor, stream of research on this issue. Hundreds of past studies in non-western cultures on newborn care, and other $\mathrm{MCH}$ issues, 
have virtually ignored grandmothers' role. What can explain this gap? In my analysis, this discrepancy points to inadequacies in the dominant conceptual frameworks used in research, of Euro-American origin, which do not take into account the structure and social dynamics of nonwestern, collectivist cultures. [16]

Most studies on newborn care in the non-western world are conceptually grounded in a western model of the nuclear family where: care for neonates is predominantly the responsibility of biological parents; the roles of women and men overlap; often grandparents are not nearby; and young parents give greater credence to doctors' advice than to that of their elders. Conceptual frameworks for research used across the non-western world, copied from the western world and oriented toward the values of individualist cultures, consistently overlook the distinct features of collectivist societies [16]. As regards newborn caregiving, most research is primarily interested in mothers' individual knowledge, attitudes and practices, and sometimes those of fathers, while giving limited attention to the wider family systems in which newborns are embedded.

Fundamental characteristics of family systems in collectivist cultures that significantly influence newborn care that should be further investigated include: gender-specific roles in families related to $\mathrm{MCH}$; multi-generational involvement in childcare; the hierarchical structure of authority among women, related to age and experience; patterns of communication and authority between sexes and generations; collective decision-making within families and the respective roles of older and younger males and females; men's involvement in different facets of childcare; and their attitudes toward the advice provide to them by older, experienced women.

It is noteworthy that much of the recent newborn research that is grounded in a wider family systems framework was conducted by researchers from the Global South. I speculate that their adoption of a more systemic framework for newborn research within multi-generational and hierarchical families is influenced by their personal experience living in more collectivist environments.

As regards men's involvement in newborn care, my review of existing research presents a consistent finding that men are rarely directly involved in newborn care and their culturallydesignated role is to provide food, financial and logistical support for newborns and their mothers, 
especially in cases of newborn illness. These findings question the frequently held assumption that men are central actors and decision-makers in all aspects of family life, often associated with the power of the patriarchy. This supposition regarding men's hegemonic role in women's and children's lives in non-western families is questioned from two angles. First, evolutionary and biological anthropologists, $[82,91,93]$ question long-standing assumptions regarding males' central role in child-rearing in human societies relative to cooperative breeding patterns where females play a leading role. Second, other concerns regarding the historical discourse which places men at the center of all family life are articulated by non-western social scientists. Nigerian anthropologist Amadiume asserts that excessive attention has been given to the patriarchal paradigm, while at the center of African families' social life is a matriarchal system which has gone unrecognized.[94] She vehemently questions widely-held assumptions about the all-encompassing authority of the patriarchy in female domains of responsibility in family life and emphasizes the importance of the matriarchy in those spaces. Similarly, from a South Asian perspective on gender dynamics, Mumtaz critiques the over-emphasis on men's influence on women's lives and calls attention to the importance of women-to-women bonds and intergenerational female relationships wherein younger women's ties with older women who are siyarni, or wise, and experienced, are particularly edifying.[95] These rarely heard critiques of the notion of men's all-encompassing authority in the lives of women and children evoke the need for greater investigation of women-centered systems of collaboration and authority within family systems.

\section{RECOMMENDATIONS}

Two major recommendations emerge from this discussion supporting the need: to reconceptualize newborn research and interventions; and to involve grandmothers in newborn interventions.

First, this discussion of the evidence on the role and influence of grandmothers on newborn health highlights the incongruity between the decisive role played by these culturally-designated newborn advisors and caregivers and the fact that most newborn policies and programs virtually ignore their influence in the lives of newborns and the vast social resource that they represent for community newborn interventions. To more effectively promote newborn health and survival I contend that there is a need for a major conceptual shift in newborn research to overcome the prevailing conceptual bias which reflects a Eurocentric view of families rather than the structure and values of more collectivist non-western societies.[7,16] Making this shift will require revision of prevailing 
conceptual frameworks and development of alternative research methodologies. This reframing should contribute to better understanding communities' emic perspective and subsequently to more effective strategies to promote newborn survival. Pioneering work by some scholars from the Global South exhibits a more systemic and culturally-grounded frame for $\mathrm{MCH}$ research on intrahousehold dynamics indicating their greater cognizance of both the structure of collectivist cultures and of the critical role played by elders within those systems.

Second, the studies reviewed here provide extensive evidence of grandmothers' role as caregivers and decision-makers in newborn care across the Global South. Most studies strongly advocate for their inclusion in future newborn interventions given their power and influence within their respective cultures and on the notion that their involvement may strengthen their knowledge and practices. While all research reviewed provides evidence of grandmothers' influence on newborn care, surprisingly, some does not explicitly recommend their inclusion in future programs. Unfortunately, there is continued reluctance to explicitly involve grandmothers in interventions addressing newborn and other $\mathrm{MCH}$ issues. This appears to be related to: the often-repeated idea that grandmothers are barriers to change; a narrow perception of grandmothers focusing on their harmful traditional practices; gender and ageist biases toward older women; and their presumed resistance to change. Policy and program planners should realize that failure to explicitly include these cultural authorities can be perceived by grandmothers themselves and by their communities as an affront to their culture and engender resistance to well-intentioned programs, thereby limiting their effectiveness. This review provides support for the use of unconventional, but culturally-grounded criteria for choosing community target groups for newborn interventions, namely, cultural authority, age and experience with newborns.

The potential for grandmother-inclusive approaches to contribute to positive health-related outcomes has been documented in several recent experiences addressing various issues related to grandmothers' areas of responsibility and expertise. Research on these innovative approaches has shown positive results in terms of strengthening grandmothers' knowledge, care-giving competencies and advice to other family members and increasing program outcomes. Encouraging results of grandmother-inclusive interventions have been reported by: Tiwari and colleagues in Nepal related to antenatal and newborn care;[96] Kumar and colleagues' in Uttar Pradesh addressing newborn care;[4] in Malawi, dealing both with newborn care by Save The Children [97] 
and with adolescent HIV prevention by Limaye and colleagues;[98] HKI in Burkina Faso addressing child nutrition [99] and in Senegal both by Newman [100] on adolescent reproductive health and by Aubel and colleagues [101] on maternal and child nutrition. These positive experiences suggest that grandmothers may not be as intransigent to change as often assumed and support the need for further experimentation with and evaluation of grandmother-inclusive interventions to address newborn and other family health issues.

\section{Summary box:}

- During the first month of life, newborns are embedded in families and in collectivist cultures in the Global South, typically multiple family members are involved in caregiving.

- Research conducted in 80 non-western cultural contexts across Africa, Asia and Latin provides evidence of the active role and influence of senior women, or grandmothers, in newborn care.

- To decrease newborn mortality, newborn health policies and interventions primarily focus on strengthening formal health services while giving limited attention to family level caregiving strategies.

- Newborn research and interventions should adopt a family systems, socio-ecological, framework in order to adequately understand and support family level caregiving.

- Grandmothers' experience and commitment to newborn survival constitutes a cultural resource, or asset, for promoting newborn survival in the Global South.

\section{Acknowledgements:}

Gratitude is expressed to Dr. Tina Grybowski and Alyssa Rychtarick for their help in identifying the literature reviewed here from diverse sources and for their inputs into earlier drafts of the paper.

\section{Declarations:}

Funding: no external funding was provided to support preparation of this paper.

Conflict of interest: No conflict of interest.

Ethics approval: Not applicable

Author's contribution: The author defined the idea for the article, conducted the literature search and wrote the manuscript.

ORCID: Judi A. Aubel, https://orcid.org/0000-0003-2304-6100

$<$ https://doi.org/10.31219/osf.io/pyc63

Judi Aubel: judiaubel@grandmotherproject.org 


\section{REFERENCES}

1. Lawn, J.E., Blencowe, H., Oza, S., et al. Every Newborn: Progress, Priorities, and Potential Beyond Survival. Lancet 2014; 384:189-205.

2. UNICEF Every Child Alive: The urgent need to end newborn deaths. New York: UNICEF 2018.

3. WHO WHO recommendations on postnatal care of the mother and newborn. Geneva: WHO 2013.

4. Kumar, V., Kumar, A., \& Darmstadt, G.L. Behavior change for newborn survival in resource-poor community settings: Bridging the gap between evidence and impact. Semin Perinatol 2010; 34:446461.

5. Paul, B. Health, Culture and Community. New York, NY: Sage Publishing: 1955.

6. Kagawa-Singer, M., Dressler, W., George, S., et al. The cultural framework for health. Washington, D.C.: National Institute for Health 2015.

7. Airhihenbuwa, C.O. Health and culture: beyond the Western paradigm. New York, NY: Sage 1995.

8. Weidman, H.H. A transcultural perspective on health behavior. In: D.S. Gochman, ed. Health Behavior: Emerging Research Perspectives. Plenun Press, NY. 1988:261-280.

9. Glass, T.A., \& McAtee, M.J. Behavioral science at the crossroads in public health: Extending horizons, envisioning the future. Soc Sci Med 2006;62:1650-1671.

10. Triandis, H.C. \& Heron, A. (Eds.) Handbook of cross-cultural psychology. Boston, MA: Allyn \& Bacon 1981.

11. Hofstede, G. Culture's Consequences. Newbury Park, CA: Sage Publishing 1984.

12. Aubel, J. and Rychtarik, A. Focus on Families and Culture. Washington, D.C.: TOPS/Grandmother Project/USAID 2015.

13. Kim, H.S., Sherman, D.K. \& Taylor, S.E. Culture and social support. Am Psychol 2008;63:6:518526.

14. Kumar,V., Kumar, A., Ghosh, A.K., et al. Enculturating science: Community-centric design of behavior change interactions for accelerating health impact. Semin Perinatol 2015;39:393-415.

15. Nussbaum, B. Ubuntu: Reflections of a South African on our Common Humanity. Reflections, 2003;4:4:21-26.

16. Kagitcibasi, C. (1996). Family and human development across cultures: A view from the other side. Lawrence Erlbaum Pubs, New Jersey. 
17. Imorou, A.B., Sambieni, E.N. \& Nansounon, C. Etudes sur les cinq pratiques familiales essentielles et les trois pratiques d'eveil essentielles au Benin. Cotounou: LASDEL 2012.

18. Kane, H. Soins des nouveau-nes: les recommandations internationals face aux enjeux sociaux de la naissance. Santé publique 2020;32:17-27.

19. Berman, P., Kendall, C. \& Bhattacharyya, K. The household production of health: Integrating social science perspectives on micro-level health determinants. Soc Sci Med 1994;38:205-215.

20. Harkness, C.M. \& Super, S. The development niche: a theoretical framework for analyzing the household. Soc Sci Med 1994;38:217-226.

21. Denham, S.A. Family Health: a framework for nursing. Pennsylvania: F. A. Davis Company 2003.

22. White, J. M. \& Klein, D. M. Family Theories. Thousand Oaks, CA: Sage Publishing 2002.

23. Mabry, P.L., Milstein, B., Abraido-Lanza, A.F., et al. Open a window on systems science research in health promotion and public. Health Educ Behav 2013; 40:1S, 5S-8S.

24. Schrijner, S. \& Smits, J. Grandparents and children's stunting in sub-Saharan Africa. Soc Sci Med 2018;205:90-98.

25. Aubel, J. The role and influence of grandmothers on child nutrition: culturally designated advisors and caregivers. Mater Child Nutr 2012; 8:19-35.

26. Prusty, R.K. \& Unisa, S. Effect of social support networks on maternal knowledge of child health in rural Odisha, India. J Health Soc Sci 2017;2:99-118

27. Altaye, D.E., Karim, A.M., Betemariam, W., et al. Effect of family conversation on health care practices in Ethiopia. BMC Pregnancy Childb 2018;18(Suppl 1):43-52

28. Piperata, B. A. Forty days and forty nights: A bio-cultural perspective on postpartum practices in the Amazon. Soc Sci Med 2008;67:1094-1103.

29. Faye, C.M., Fonn, S. \& Kimani-Murage, E. Family influences on child nutritional outcomes in Nairobi's informal settlements. Child Care Health Dev 2018;45:509-517.

30. Adama, E., Bayes, S. \& Sundin, D. Parents' experiences of caring for preterm infants after discharge with grandmothers as their main support. J. Clin. Nurs. 2017; Sep27(17-18):3377-3386.

DOI:10.1111/jocn.13868

31. Buitron, F. \& Sandoval, M. Cambios biologicos y socio culturales en el puerperio desde las experiencias de las abuelas, madres et futuras madres. 2018;Thesis, Universidad del Ecuador, Quito.

32. Gross, F., Pacheco, I.C., Oliveira, N.M., et al. Influence of grandmothers on infant feeding: what they say to their daughters and granddaughters. Acta Paul Enferm 2011;24:534-540.

33. Karmacharya, C., Cunningham,K. , Choufani, J. et al. Grandmothers' knowledge positively influences maternal knowledge and infant and young child feeding practices. Public Health Nutr 2017;20: 2114-2123. 
34. WHO/UNICEF. Every Newborn: an action plan to end preventable deaths. Geneva, WHO; 2014.

35. Morgan, A. \& Ziglio, E. Revitalising the evidence base for public health: An assets model. Promotion and Education 2007; Suppl 2:17-22.

36. Sibley, L.M., Amare, Y., Abebe, S.T., et al. Appropriateness and timeliness of care-seeking for complications of pregnancy and childbirth in rural Ethiopia. J Health Pop Nutr 2017;36(Suppl 1), 50.

37. Gupta, M., Aborigo, R., Adongo, P., et al. Grandmothers as gatekeepers? The role of grandmothers in influencing health-seeking for mothers and newborns in rural northern Ghana. Glob Public Health 2015;10:1078-1091.

38. Bazzano, A., Kirkwood, B., Tawiah-Agyemang, C., et al. Beyond symptom recognition: Careseeking for ill newborns in rural Ghana. Trop Med Int Health 2008;13:123-128.

39. World Vision Qualitative Study on Maternal and Child Health and Nutrition in Guerou and Mbagne, Mauritania. Nouakchott: World Vision 2019

40. Scott, M., Malde, B., King, C., et al. Family networks and infant health promotion: a mixedmethods evaluation from a cluster randomized controlled trial in rural Malawi. BMJ Open Access 2018;8:1-10.

41. Bezner Kerr, R., Dakishoni, L., Shumba, L., et al. "We Grandmothers know plenty": Breastfeeding, complementary feeding and the multifaceted role of grandmothers in Malawi. Soc Sci Med 2008; 66:1095-1105.

42. Medecins du Monde Alimentation et soins aux enfants: Pratiques, prises de decisions et facteurs de changement dans trios départements de la région de Tahoua. Niamey: Medecins du Monde 2008.

43. Okunola, R. Formative Assessment of infant and young child feeding practices: Nigeria. Washington, DC: IYCN \& USAID 2011.

44. MCHIP/USAID Examining factors associated with stunting in Lower Egypt in comparison to Upper Egypt. Washington DC: MCHIP/USAID 2014.

45. Darmstadt, G.L., Hussein, M.H., Winch, P.J., et al. Neonatal home care practices in rural Egypt during the first week of life. Trop Med Intl Health 2007;12:783-797.

46. Ouoba, M. D. Rôles des grand-mères dans l'éducation et la perpétuations des savoirs locaux et modernes en matière de santé/nutrition et bien-être des enfants et des femmes. Ouagadougou, Burkina Faso: HKI \& Terre des Hommes. 2008.

47. Alive and Thrive. Formative Research to Support Improved Infant Feeding in Burkina Faso. Washington, D.C.: FHI360 2015.3 
48. FSAU. Somali knowledge, attitude and practices study: Infant and young child feeding and health seeking practices. Nairobi: FAO 2007.

49. Niang, C.I. Recherche formative sur la sante péri/néonatale a Kébémere, Senegal. Dakar: BASICS/USAID 2003.

50. COUNTERPART Recherche formative sur la nutrition infantile et maternelle. Dakar: COUNTERPART 2011.

51. Fjeld, E., Siziya, S., Katepa-Bwalya, M., et al. 'No sister, the breast alone is not enough for my baby' $A$ qualitative assessment of potentials and barriers in the promotion of EBF in southern Zambia. Int BF J 2008;3:26.

52. Iganus, R., Hill, Z., Manzi, F. et al. Roles and responsibilities in newborn care in four African sites. Trop Med Int Health 2015;20:1258-1264.

53. AgErless, M. Grossesse et suivi de l'accouchement en milieu Touareg. Montpelier: Memoire de I'EHESS:2007.

54. RESEADE Rapport de l'étude qualitative relative aux pratiques familiales essentielles pour la prise en charge intégrée des maladies de l'enfant. Bamako: UNICEF 2009.

55. Diarra, D. L'étude du Role des grand-mères bambara dans la prise en charge socio-educative des femmes et des nouveau-nes dans le milieu urbain. Mémoire. Bamako: INFTS 2009.

56. Mukunya, D., Nankabirwa, V., Ndeezi, G., et al. Key Decision makers and actors in selected newborn care practices: A community-based survey in northern Uganda. Int J Environ Res Public Health 2019;May 16(10):1723. doi:10.3390/ijerph16101723

57. Mohan, P., lyengar, S.D., Agarwal, K., et al. Care-seeking practices in rural Rajasthan: barriers and facilitating factors. J Perinatol 2008;28:S31-S37.

58. Alive and Thrive. Nutrition practices in Bihar: Results of a formative research study. Washington D.C.: FHI360 2017.

59. Kaushal, M., Aggarwal, R., Singal, A., et al. Breastfeeding practices and health-seeking behavior for neonatal sickness in a rural community. J Trop Pediatr 2005;51:366-376.

60. Sharma, M. \& Kanani, S. Grandmothers' Influence on Child Care. Indian J Pediatr 2006;73:295298.

61. Khadduri, R., Marsh, D., Rasmussen, B. et al. Household knowledge and practices of newborn and maternal health in Haripur District, Pakistan. J Perinatol 2008;28:182-7.

62. Hillenbrand, E. Maternal malnutrition and poverty as perceived barriers to exclusive breastfeeding in rural Bangladesh. New York, NY: Helen Keller International 2012. 
63. Gryboski, K. L. Maternal and non-maternal time-allocation to infant care and care during infant illness in rural Java, Indonesia. Soc Sci Med 1996;43:209-219.

64. Susin, L.R.O., Giugliani, E.R.J. \& Kummer, S.C. Influence of grandmothers on breastfeeding practices. Rev. Saúde Publica 2005;39:1-6.

65. González, T. \& Hernández, S. Lactancia materna en México: Recomendaciones para el diseño e implementación de una política nacional multisectorial de promoción, protección y apoyo de lactancia materna en México. México: Academia Nacional de Medicina 2016.

66. Sedo-Masis, P. \& Urena-Vargas. M. Papel social de las abuelas en el seno familiar: Percepciones de un grupo de mujeres mayores residentes en comunidades urbanas de Costa Rica. Red Latinoamericano de Gerontólogia 2007.

67. Alvarado, B.E, Tabare, R.E., Delisle, H. \& Zunzunegui, M.V. Creencias maternas, praticas de alimentacion y estado nutricional en ninos Afro-Coumbianos. Arch Latinoam Nutr 2005;55:1-13.

68. Kesterton, A.J. \& Cleland, J. Neonatal care in rural Karnataka: Healthy and harmful practices, the potential for change. BMC Pregnancy Child 2009;9:20.

69. Aborigo, R.A., Moyer, C.A., Rominski, Adongo, S.P., et al. Infant nutrition in the first seven days of life in rural northern Ghana. BMC Pregnancy Childbirth 2012;12:1-10.

70. Ministero de la Salud. Conocer las conductas y praticas que aplican las mujeres y las familias en el cuidado del embarazo, parto y del recien nacido. Managua, Nicaragua : Ministero de la Salud 2005.

71. Lama, T.P., Khatry S.K., Katz, J., et al. Illness recognition, decision-making, and care-seeking for maternal and newborn complications: a qualitative study in Sarlahi District, Nepal. J Health, Popul Nutr 2017;36(Suppl 1):45.

72. Bang, A.T., Bang, R.A., Reddy, H.M., et al. Methods and the baseline situation in the field trial of home-based neonatal care in Gadchiroli, India. J Perinatol 2005;25:S11-S17.

73. Otoo, G.E., Larkey, A.A. \& Perez-Escamilla, R. Perceived incentives and barriers to exclusive breastfeeding among periurban Ghanian women. J Hum Lact 2009;25:34-41.

74. Diagana, M.M. \& Kane, H. Alimentation des nourrissons a Nouakchott: entre recommandations medicales et instructions des grand-meres. Sante publique 2016;28:235-343.

75. Turnbull-Plaza, B., Escalante-Izeta, E., \& Klunder-Klunder, M. Papel de las redes sociales en la lactancia materna exclusiva. Rev Med Inst Mex Seguro Soc 2006;44:97-104.

76. Choudhury, N., Moran, A.C., Alam, M.A., et al. Beliefs and practices during pregnancy and childbirth in urban slums of Dhaka, Bangladesh. BMC Public Health 2012;12:791.

https://doi.org/10.1186/1471-2458-12-791 
77. Masvie, $\mathrm{H}$. The role of Tamang mothers-in-law in promoting breastfeeding in Makwanpur District, Nepal. Midwifery 2006;22:23-31.

78. Matinga, P.U. Models for inclusive and equitable sexual \& reproductive health project. Lilongwe: CARE 2005.

79. Kumar,V., Kumar, A., Ghosh, A.K., et al. Enculturating science: Community-centric design of behavior change interactions for accelerating health impact. Semin Perinatol 2015;39:393-415. $\rightarrow$ 14

80. Campos-Navarro, R. El Empacho: Una enfermedad popular latinoamericano. Cuad Hist Salud Publica 2007;Dic:102. http://scielo.sld.cu/scielo.php?script=sci_arttext\&pid=S004591782007000200004\&lng=es.

81. Schuler, C., Ntow, G.E. \& Agbozo, F. Mothers' experiences with neonatal care for LBW infants at home; a qualitative study in Hohoe Municipality in Ghana. J Pediatr Nurs 2019; Mar-Apr 45:e44e52.

82. Sear, R. \& Coall. D. How much does family matter? Cooperative breeding and the demographic transition. Pop Dev Rev 2011;37:81-112.

83. Steuart, G. Social and Cultural Perspectives. Umstead Distinguished Lecture;1978; Raleigh, NC.

84. Adams, A.M., Madhavan, S. \& Simon, D. Women's social networks and child survival in Mali. Soc Sci Med 2002;54:165-178.

85. Morrison, J., Dulal, S., Harris-Fry, H., et al. Formative qualitative research to develop community-based interventions addressing low birth weight in the plains of Nepal. Public Health Nutr 2018;21:377-384.

86. Senanayake, J.P., Weerawarna, H., Karunaratne, K.W. et al. Do babies need water in Sri Lanka? Ceylon Medical Journal 1999;44,:26-129.

87. Okuga M., Waiswa P. Mandu R., et al. Illness recognition and care-seeking for maternal and newborn complications in rural eastern Uganda. J Health Popul Nutr 2017;36(Suppl

1):doi:10.1186/s41043-017-0125-x.

88. Charlet D., Moran A.C \& Madhavan S. Summary findings from a mixed methods study on identifying and responding to maternal and newborn illness in seven countries. $J$ Health Popul Nutr 2017;36(Suppl 1)48.

89. Aruldas K., Kant A. \& Mohanan, P. S. Care-seeking behaviors for maternal and newborn illnesses among self-help group households in Uttar Pradesh, India. J Health Popul Nutr 2017;36(Suppl 1):49. doi: 10.1186/s41043-017-0121-1 
90. Dumbaugh, M., Tawiah-Agyemang, C., Manu, A., et al. Perceptions of attitudes towards and barriers to male involvement in newborn care in rural Ghana, West Africa: A qualitative analysis. BMC Pregnancy Child 2014;14:269-278.

91. Scelza, B.A. \& K.Hinde. A biocultural study of grandmothering during the perinatal period. HumanNature 2019;30;371-397.

92. Hrdy, S.B. Mothers and Others: The evolutionary origins of mutual understanding. Cambridge: Harvard University Press 2009.

93. Lovejoy, C. The origin of man. Science 1981;211:341-350.

94. Amadiume, I. Reinventing Africa: Matriarchy, Religion and Culture. London, UK: Zed Books 1997.

95. Mumtaz, Z. \& Salway, S. Understanding gendered influences on women's reproductive health in Pakistan: Moving beyond the autonomy paradigm. Soc Sci Med 2009;68:349-1356.

96. Tiwari, D.P., Bhatta, K., Tirmizi, N., et al. Effects of Co-empowering mother and mother-in-law on the prenatal, delivery, postnatal knowledge and practices in the Far West Region of Nepal. Am J Med Sci 2014;3:1-12.

97. Van Zyl, M. The Ekwendeni Agogo Approach: Grandparents as agents of change for newborn survival. Lilongwe: Save The Children, 2010.

98. Limaye, R.J., Rimal, R.N., Mkandawire, G., et al. Tapping Into Traditional Norms for Preventing HIV and Unintended Pregnancy: Harnessing the Influence of Grandmothers (Agogos) in Malawi. Int Q Community Health Educ 2015;36(1):53-70. DOI: 10.1177/0272684X15615446

99. Helen Keller International. Impact de l'approche grand-mères en matière de santé et nutrition dans les villages d'intervention d'HKI. Burkina Faso : Hellen Keller International 2010.

100. Newman, A. Evidence Synthesis Review of The Grandmother Project's “Girls' Holistic Development" Programme. Institute for Reproductive Health, Washington, D.C.: Georgetown University for USAID 2017.

101. Aubel, J., Touré, I. \& Diagne, M. Senegalese Grandmothers improve maternal and child nutrition practices: "The guardians of tradition are not averse to change". Soc Sci Med 2004;59:945-959.

\section{Figure 1:}

Aubel, J. \& A. Rychtarik. Focus on Families and Culture. Washington, D.C. TOPS/Grandmother Project/USAID 2015.

\section{Unpublished - Master's Theses \& Doctoral Dissertations}


Ramos, A. La percepción y conocimientos sobre lactancia materna (LM) en abuelas y su influencia en la práctica de la lactancia materna de hijas y nueras: un estudio cualitativo en un centro de salud de Cuernavaca, Morales. (Masters thesis). Instituto Nacional de Salud Pública de México 2014.

Barrett, J.B. Doctors, clerics, healers, and neighbors: Religious influences on maternal and child health in Uzbekistan. (Doctoral Dissertation) University of Texas, Austin 2008.

Bixiones, C. Breastfeeding among Indigenous Guatemalan mothers: A study of the barriers to optimal breastfeeding practices. (Master's thesis) University of North Carolina, Chapel Hill 2007.

Kadima, S. N. Impact of a formal antenatal breastfeeding education program on the acceptance and attitudes towards exclusive breastfeeding among mothers in rural Haiti. (Master's thesis) Duke Global Health Institute, Duke University 2018. 